\title{
VORACITY OF COCCINELLID SPECIES ON DIFFERENT PHENOLOGICAL STAGES OF THE OLIVE PEST SAISSETIA OLEAE (HOMOPTERA, COCCIDAE)
}

\author{
S.A.P. SANTOS ${ }^{1} *-$ J.A. PEREIRA ${ }^{1}-$ L.M. TORRES ${ }^{2}-$ A.J.A. NOGUEIRA ${ }^{3}$ \\ ${ }^{1}$ CIMO \& Escola Superior Agrária, Instituto Politécnico de Bragança, Apt. 1172, 5301-855 \\ Bragança, Portugal (phone: +351 273303 371; fax: + 273325 405) \\ ${ }^{2}$ CITAB \& Universidade de Trás-os-Montes e Alto Douro, Apt. 1013, 5001-801 Vila Real, \\ Portugal (phone: +351259350 515; fax: + 351259350 542) \\ ${ }^{3}$ CESAM \& Departamento de Biologia, Universidade de Aveiro Campus de Santiago, 3810-193 \\ Aveiro, Portugal (phone: +351 234370 768; fax: +351 234426 408) \\ *Corresponding author \\ e-mail: saps@ipb.pt \\ (Received $26^{\text {th }}$ June 2008 ; accepted $14^{\text {th }}$ December 2009)
}

\begin{abstract}
Coccinellidae are well known predators in agroecosystems. In olive groves they may exert control against scales, such as the black scale, Saissetia oleae (Olivier, 1791). Laboratory studies on the consumption of three phenological stages (eggs, first and second instar nymphs) of $S$. oleae by four coccinellid species (Chilocorus bipustulatus, Scymnus (Pullus) subvillosus, Scymnus (Mimopullus) mediterraneus and Scymnus (Scymnus) interruptus) were carried out. C. bipustulatus presented a significantly high consumption of eggs, first and second instar nymphs compared with the other species. All coccinellids consumed eggs and first instar nymphs; however the second instar nymphs were only consumed by $S$. interruptus and $C$. bipustulatus. In a second experiment, larval stages of $C$. bipustulatus were reared on different phenological stages of $S$. oleae. Coccinellid larvae fed with eggs or first instar nymphs completed their life cycle, contrarily to those that were fed with second instar nymphs. The apparent voracity of $C$. bipustulatus on the different phenological stages of $S$. oleae is an aspect that suggests the possible use of this coccinellid species in biological control programs against this pest in olive groves.
\end{abstract}

Keywords: Predation, Chilocorus bipustulatus, Pullus (Mimopullus) mediterraneus, Scymnus (Pullus) subvillosus, Scymnus (Scymnus) interruptus, black scale.

\section{Introduction}

In the Mediterranean countries, the black scale, Saissetia oleae (Olivier, 1791), is an important pest in the olive grove and natural enemies belonging to the Coccinellidae family are known to be associated with this pest [1, 2, 3, 7]

Voracity studies intend to investigate the potential of a natural enemy to consume a specific prey. This elucidation about the predatory characteristics of coccinellids is the basis for developing management strategies to successfully combat black scale infestations. Successful natural control of pests depends on the fact that a predator kills or consumes a sufficient number of pest individuals to maintain its density at a low level [13]. Such information would be useful for determining which developmental stage of $S$. oleae is the most predated and will facilitate further laboratory rearing of these insects, which is a prime objective in a biological control program [12].

Coccinellid species like Chilocorus bipustulatus (L.), Scymnus (Pullus) subvillosus (Goeze), Scymnus (Mimopullus) mediterraneus Iablokoff-Khnzorian and Scymnus 
interruptus (Goeze) are common in the olive grove of the Mediterranean region and both adults and larvae are predaceous stages $[1,3]$. Field studies showed that the most predated phenological stages of $S$. oleae by coccinellids were potentially the first and second instar nymphs (Santos et al., unpublished data). Moreover, S. oleae eggs have been used to feed different coccinellid species in laboratory cultures [1, 2, 3]. Therefore, it is important to gain insight about the effective predated stages of $S$. oleae by coccinellids. This information will help on further studies concerning the natural control of $S$. oleae by coccinellids in field and also the maintenance of laboratory cultures of coccinellids reared on S. oleae.

The objective of this study was to investigate, under controlled conditions, the ability of selected coccinellid species to use different phenological stages of $S$. oleae as food item.

\section{Material and Methods}

To study the consumption of different phenological stages of $S$. oleae by coccinellid species, two experiments were carried out: (1) screening of coccinellids voracity using adult stages, and (2) assessment of feeding rates, along the life-cycle of the most voracious coccinellid species, using eggs, first instar and second instar nymphs of $S$. oleae as food items.

To perform the first experiment, specimens belonging to the four most common coccinellid species namely, $S$. mediterraneus, $S$. subvillosus, $S$. interruptus and $C$. bipustulatus, were captured by the beating technique in an organic olive grove Valbom-dos-Figos ( $41^{\circ} 33^{\prime} 4^{\prime \prime}$ N, $7^{\circ}$ 8' 43' W) - located near Mirandela, Trás-osMontes (north-east of Portugal). The three different phenological stages of S. oleae (eggs, first and second instar nymphs) were collected with the leaf.

In the laboratory, 30 coccinellid specimens of each species were placed in individual Petri dishes ( $9 \mathrm{~cm}$ diameter $\times 2 \mathrm{~cm}$ height) with moistened filter paper covering the bottom of the box and starved during 24 hours.

Each species was separated in three groups of ten specimens. Each group was fed daily with a different phenological stage of $S$. oleae during five days: group 1 was fed with 100 eggs/day, group 2 with 10 first instar nymphs/day and the third group with 10 second instar nymphs/day. During five days, specimens were allowed to forage for $24 \mathrm{~h}$ after which the food was renewed and the total number of prey eggs, N1 nymphs or N2 nymphs was recorded.

Based on the results of the first experiment, $C$. bipustulatus was selected to perform the second experiment where the consumption of eggs and first and second instar nymphs of $S$. oleae by larval stages and adults of $C$. bipustulatus was studied.

C. bipustulatus adult specimens were captured in the same grove mentioned above. In the laboratory, they were coupled in Petri dishes $(9 \mathrm{~cm}$ diameter $\times 2 \mathrm{~cm}$ height $)$ with moistened filter paper covering the bottom of the box and fed with S. oleae eggs. Newly laid eggs were transferred individually to a clean Petri dish with a soft brush and daily observed till hatching. Forty-five recently emerged $\mathrm{L}_{1}$ larvae were divided in three groups with fifteen specimens. Group 1 was supplied with 100 eggs/day, group 2 with 10 first instar nymphs/day and group 3 with 10 second instar nymphs/day. Each Petri dish was examined daily to record consumption. Moulting marked the differentiation between larval stages. Freshly emerged adults were used to make the same set of experiments as in larval stages. 
All experiments were conducted at a temperature of $25 \pm 2^{\circ} \mathrm{C}$ and under a $16 \mathrm{~L}: 8 \mathrm{D} \mathrm{h}$ regime.

\section{Data analysis}

Univariate statistical analyses were performed using the Statistica Statistical package, version 7.0 [15]. Data were evaluated for normality and homogeneity of variances with Kolmogorov-Smirnov test and Bartlett's test, respectively. One-way ANOVA was used to compare the consumption of $S$. oleae phenological stages by each coccinellid species. A significant level of 0.05 was used for all statistical tests.

\section{Results and Discussion}

In the first experiment, the food intake by the four coccinellid species tested was maintained constant during the five days, except in the case of the consumption of the first instar nymphs by $S$. interruptus that varied significantly (Table 1). C. bipustulatus showed a significantly high consumption for all phenological stages of $S$. oleae with a mean total consumed eggs, first instar and second instar nymphs respectively of $381.3 \pm$ 15.3 (mean \pm standard error of the mean $-\mathrm{SE}, \mathrm{n}=10$ ), $8.6 \pm 0.7$ and $15.3 \pm 1.9$, when compared with the other species tested (Fig. 1). S. interruptus consumed a mean total of $160.1 \pm 6.9$ eggs, $5.2 \pm 0.7$ first-instar nymphs and $0.3 \pm 0.2$ second-instar nymphs and S. subvillosus consumed $150.4 \pm 20.5$ eggs and $4.5 \pm 1.2$ first-instar nymphs. On the other hand, $S$. mediterraneus showed a significantly low consumption of eggs and the lowest consumption of the first instar nymphs, with a mean total of respectively $52.9 \pm$ 4.5 and $2.8 \pm 0.4$, relatively with the other species. Second instar nymphs were not consumed by $S$. mediterraneus and S. subvillosus.

Table 1. Consumption by coccinellids species $(n=10)$ of three phenological stages of Saissetia oleae (mean \pm standard error of the mean) during five days of experiment.

\begin{tabular}{|c|c|c|c|c|c|c|c|c|}
\hline \multirow{2}{*}{ Coccinellid species } & \multirow{2}{*}{$\begin{array}{l}\text { Food } \\
\text { item }\end{array}$} & \multicolumn{5}{|c|}{ Days } & \multirow{2}{*}{\multicolumn{2}{|c|}{$F_{4,45}$}} \\
\hline & & 1 & 2 & 3 & 4 & 5 & & \\
\hline \multirow[t]{3}{*}{ Chilocorus bipustulatus } & eggs & $81.6 \pm 3.75$ & $76.3 \pm 3.04$ & $77.9 \pm 3.51$ & $75.4 \pm 3.04$ & $70.1 \pm 6.27$ & $1.04 \mathrm{n}$ & 1.s. \\
\hline & $\mathrm{N} 1$ & $2.6 \pm 0.40$ & $1.8 \pm 0.44$ & $1.5 \pm 0.27$ & $1.2 \pm 0.25$ & $1.5 \pm 0.34$ & $2.37 \mathrm{n}$ & 1.s. \\
\hline & $\mathrm{N} 2$ & $4.1 \pm 0.71$ & $3.5 \pm 0.50$ & $2.9 \pm 0.28$ & $2.6 \pm 0.50$ & $2.2 \pm 0.36$ & $2.34 \mathrm{n}$ & 1.s. \\
\hline \multirow[t]{3}{*}{ Scymnus (Mimopullus) mediterraneus } & eggs & $10.5 \pm 1.89^{a b}$ & $12.9 \pm 1.38^{\mathrm{ab}}$ & $13.9 \pm 1.55^{\mathrm{a}}$ & $7.5 \pm 1.30^{\mathrm{b}}$ & $8.1 \pm 1.49^{\mathrm{ab}}$ & $3.40 *$ & \\
\hline & N1 & $0.9 \pm 0.18$ & $0.8 \pm 0.25$ & $0.5 \pm 0.17$ & $0.4 \pm 0.22$ & $0.2 \pm 0.13$ & $2.20 \mathrm{n}$ & 1.s. \\
\hline & $\mathrm{N} 2$ & 0 & 0 & 0 & 0 & 0 & - & - \\
\hline \multirow[t]{3}{*}{ Scymnus (Pullus) subvillosus } & eggs & $40.7 \pm 6.49$ & $32.8 \pm 5.36$ & $27.9 \pm 5.57$ & $27 \pm 4.32$ & $22 \pm 3.39$ & $1.90 \mathrm{n}$ & n.s. \\
\hline & N1 & $1.5 \pm 0.31$ & $0.9 \pm 0.28$ & $0.7 \pm 0.33$ & $0.7 \pm 0.37$ & $0.7 \pm 0.40$ & $1.04 \mathrm{n}$ & n.s. \\
\hline & $\mathrm{N} 2$ & 0 & 0 & 0 & 0 & 0 & - & - \\
\hline \multirow[t]{3}{*}{ Scymnus (Scymnus) interruptus } & eggs & $30.7 \pm 5.34$ & $36.6 \pm 3.63$ & $33 \pm 3.16$ & $34.6 \pm 3.56$ & $25.2 \pm 3.91$ & $1.21 \mathrm{n}$ & n.s. \\
\hline & N1 & $2 \pm 0.37^{\mathrm{a}}$ & $1.6 \pm 0.40^{\mathrm{ab}}$ & $0.8 \pm 0.20^{\mathrm{bc}}$ & $0.6 \pm 0.22^{\mathrm{bc}}$ & $0.2 \pm 0.13^{\mathrm{c}}$ & $6.85 *$ & *** \\
\hline & $\mathrm{N} 2$ & $0.2 \pm 0.13$ & 0 & 0 & $0.1 \pm 0.10$ & 0 & $1.44 \mathrm{n}$ & n.s. \\
\hline
\end{tabular}

Means sharing the same letter within rows are not significantly different at $p>0.05$. ns- non significant. 

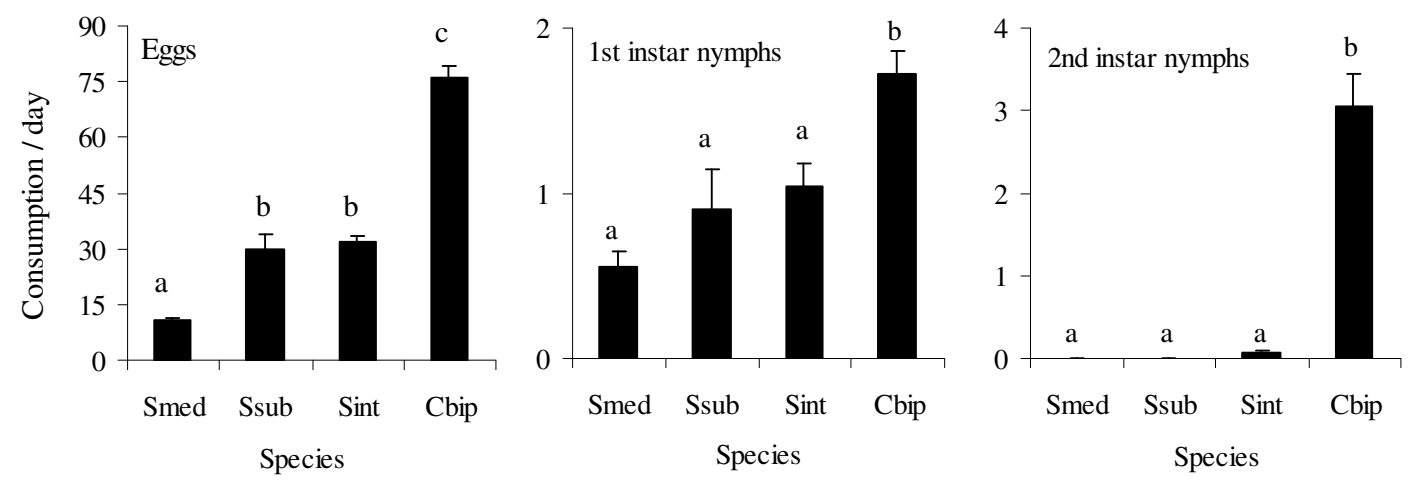

Figure 1. Consumption (mean \pm standard error of the mean) of the three phenological stages of Saissetia oleae by the four coccinellid species tested: Smed - Scymnus mediterraneus, Ssub Scymnus subvillosus, Sint - Scymnus interruptus, Cbip - Chilocorus bipustulatus. $n=10$. Different axis scales were used. Bars sharing the same letter are not significantly different at $P>0.05$.

In laboratory studies [1] showed that it was possible to obtained consecutive generation of $C$. bipustulatus fed with $S$. oleae (phenological stage was not specified) but unsuccessful attempts were obtained for $S$. subvillosus. Also, [2] showed that $S$. mediterraneus completed its life cycle consuming a large amount of eggs of $S$. oleae.

The consumption of the different phenological stages of $S$. oleae depends mostly on the characteristics of the tegument of the prey [5], the relation between the sizes of predator and prey and also the nutritional quality of the prey [11]. Easily penetrated covers are more likely to be suppressed than thick covers [5]. In this way, it was probable that first instar nymphs are softer and easier to handle by smaller coccinellid species (e. g. S. mediterraneus) than the second instar nymphs. On the other hand, because of their large size, adult $C$. bipustulatus can easily chew through the covers of greater nymphs that provide higher energetic gain than smaller nymphs [10]. Thus, the consumption of each phenological stage of $S$. oleae can be considered as a trade-off between its energetic value and the morphological characteristic of the integument that makes predation by coccinellids difficult.

The consumption of $S$. oleae eggs by the majority of coccinellid species will be difficult under field conditions due to the hard integument of the egg-bearing females. Eventually, only $C$. bipustulatus can predate egg-bearing females because it possesses highly modified mandibles that are unique to the genus - they are acutely angled with a single tooth at their apex, which can be inserted between the scale and the substrate [5]. Other coccinellid species consume preferentially first and second instar nymphs of $S$. oleae that are abundant and accessible stages in summer and autumn in olive groves [8; Santos et al., unpublished data]. Nonetheless, due to its high nutritive value, eggs can be used as food for rearing laboratory cultures since they were successfully fed by all coccinellid species.

In the second experiment, the consumption of $S$. oleae eggs and first instar nymphs by the successive larval stages of $C$. bipustulatus increased with their development. The general pattern of food consumption by larval stages showed a gradual increase immediately after each moult but in third and fourth larval stages, a small decline 
occurred as larvae approached the ecdysis (Fig. 2). No differences were found between the developmental period of specimens fed with eggs and those fed with first nymphal nymphs. [9] observed a similar pattern in all larval stages of Chilocorus nigritus (F.) reared on the cyanophyllum scale Abgrallaspis cyanophylli (Signoret). A total mean of $976 \pm 11.22$ eggs of $S$. oleae were consumed by each larva of $C$. bipustulatus. First instar larvae consumed $3.6 \%$, second instars $9.5 \%$, third instars $27.3 \%$ and fourth instars $59.6 \%$ of the total eggs intake. Considering the intake of first instar nymphs of S. oleae, a mean total number of $86 \pm 6.1$ was consumed by each larva of $C$. bipustulatus, where first instar larvae consumed $10.3 \%$, second instar $12.2 \%$, third instar $26.5 \%$ and fourth instar $51.0 \%$ of total intake. Compared with $C$. nigritus, the consumption by first instar larvae of $C$. bipustulatus was generally high and the fourth very low - 3 and $73 \%$ respectively [9].

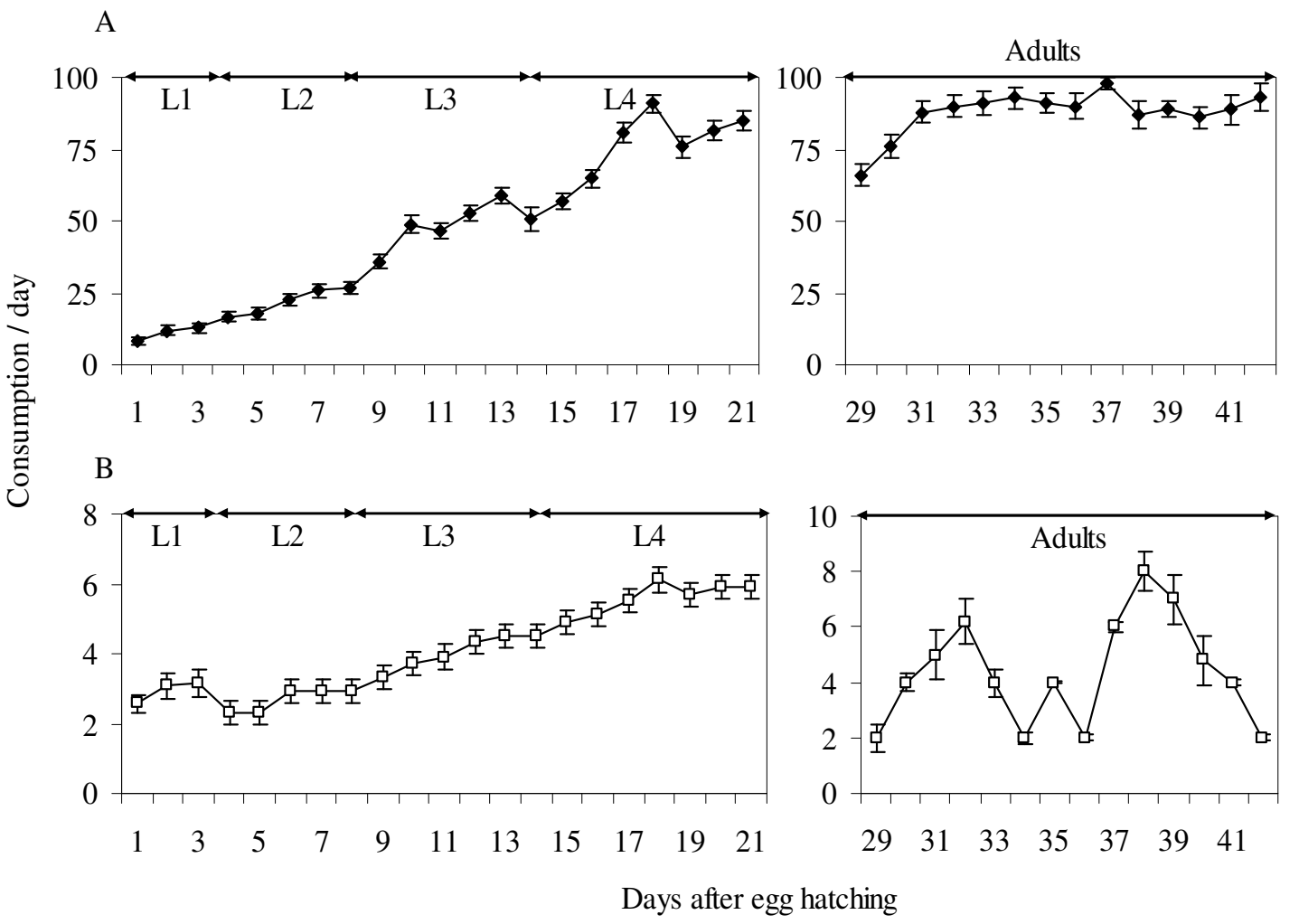

Figure 2. Consumption of eggs (A) and first instar nymphs (B) (mean $\pm S E)$ of Saissetia oleae by Chilocorus bipustulatus larvae and adult stages. Different axis scales were used. $n=15$.

The egg consumption by adults increased in the first six days after eclosion and then it remained constant till the end of the experiment (Figure 2). According [9], adult food intake in coccidophagous coccinellids is known to be low after eclosion, increasing gradually to a peak at the end of the first week. Each adult consumed a mean of $1227 \pm$ 51.98 eggs after 14 days of the experiment. The consumption of the first instar nymphs increased in the first four days and a total mean of $61 \pm 11.2$ first instar nymphs of $S$. oleae was consumed by each adult specimen after 14 days of experiment.

None of the second instar nymphs supplied were totally consumed by the first larval specimens of $C$. bipustulatus, which only developed to the second instar and 
consequently, the life cycle was not completed. As a result, alternative preys should be essential items in the first larval stages of this coccinellid species to successfully complete its life cycle. Despite their polyphagy, coccinellid adults tend to feed more certain types of food [6] and the beneficial effect that food has on individual predators leads to increased rates of growth, development and fertility, and decreased rates of mortality [4].

This study provides a better understanding of the consumption of different phenological stages of $S$. oleae by coccinellid species and the capacity of both larvae and adult stages of $C$. bipustulatus to feed on this pest and complete their life-cycles. The apparent voracity of $C$. bipustulatus on the different phenological stages of $S$. oleae is an attribute that should make it an important predator contributing for the natural biological control of the pest in the olive grove. Moreover, the larva is the most voracious stages of coccinellids [14], requiring great amounts of food to grow up rapidly. This aspect supports the likely use of this coccinellid species in biological control programs against $S$. oleae. In this context, the mass release of larval specimens, particularly the most resistant third instar larvae, can be done in order to maximize the predaceous action of $C$. bipustulatus in the olive grove.

Acknowledgments. This study was founded by projects -AGRO 236 "Protecção contra pragas em olivicultura biológica" and AGRO 482 "Protecção contra pragas do olival numa óptica de defesa do ambiente e do consumidor"

\section{REFERENCES}

[1] Argyriou, L.C., Katsoyannos, P. (1977): Coccinellidae species found in the olive-groves of Greece. - Annales de L'Institut Phytopathologique Benaki 11: 331-345.

[2] Ba M'hamed, T., Chemseddine, M. (2001): Assessment of temperature effects on the development and fecundity of Pullus mediterraneus (Col., Coccinellidae) and consumption of Saissetia oleae eggs (Hom., Coccoida). - Journal of Applied Entomology. 125: 527-531.

[3] Ba M'hamed, T., Chemseddine, M. (2002): Selective toxicity of some pesticides to Pullus mediterraneus Fabr. (Coleoptera: Coccinellidae), a predator of Saissetia oleae Bern. (Homoptera: Coccoidea). - Agricultural and Forest Entomology 4: 173-178.

[4] Begon, M., Harper, J.L., Townsend, C.R. (1996): Ecology- Individuals, Populations and Communities. $3^{\text {rd }}$ Edition. - Blackwell Science, Oxford.

[5] Honda, J.Y., Luck, R.F. (1995): Scale morphology effects on feeding behavior and biological control potential of Rhyzobius lophanthae (Coleoptera: Coccinellidae). Annals of the Entomological Society of America 88: 441-450.

[6] Iperti, G. (1999): Biodiversity of predaceous coccinellidae in relation to bioindication and economic importance. - Agriculture, Ecosystems and Environment 74: 323-342.

[7] Magro, A., Hemptinne, J.L. (1999): The pool of Coccinellids (Coleoptera: Coccinellidae) to control Coccids (Homoptera: Coccoidea) in Portuguese citrus groves. - Boletín de Sanidad Vegetal "Plagas" 25: 311-320.

[8] Pereira, J.A.C. (2004): Bioecologia da cochonilha negra, Saissetia oleae (Olivier), na oliveira, em Trás-os-Montes. PhD Thesis. Universidade de Trás-os Montes e Alto Douro, Vila Real.

[9] Ponsonby, D.J., Copland, M.J.W. (2000): Maximum feeding potential of larvae and adults of the scale insect predator, Chilocorus nigritus with a new method of estimating food intake. - Biocontrol 45: 295-310. 
[10] Provost, C., Lucas, E., Coderre, D., Chouinard, G. (2006): Prey selection by the lady beetle Harmonia axyridis: the influence of prey mobility and prey species. - Journal of Insect Behavior 19: 265-277.

[11] Roger, C., Coderre, D., Boivin, G. (2000): Differential prey utilization by the generalist predator Coleomegilla maculata lengi according to prey size and species. - Entomologia Exprimentalis et Applicata 94: 3-13.

[12] Sahayaraj, K., Paulraj, M.G. (2001): Rearing and life table of reduviid predator Rhynocoris marginatus Fab. (Het., Reduviidae) on Spodoptera litura Fab. (Lep., Noctuidae) larvae. - Journal of Applied Entomology 125: 321-325.

[13] Sengonca, C., Al-Zyoud, F., Blaeser, P. (2005): Prey consumption by larval and adult stages of the entomophagous ladybird Serangium parcesetosum Sicard (Col., Coccinellidae) on the cotton whitefly, Bemisia tabaci (Genn.) (Hom., Aleyrodidae), at two different temperatures. - Journal of Pest Science 78: 179-186.

[14] Stathas, G.J. (2000): Rhyzobius lophanthae prey consumption and fecundity. Phytoparasitica 28: 1-9.

[15] StatSoft, Inc. (2004): STATISTICA (data analysis software system), version 7. www.statsoft.com. 